\title{
Digital rock physics approach to simulate hydraulic effects of anhydrite cement in Bentheim sandstone
}

\author{
Maria Wetzel $^{1,2}$, Thomas Kempka ${ }^{1,2}$, and Michael Kühn ${ }^{1,2}$ \\ ${ }^{1}$ GFZ German Research Centre for Geosciences, Fluid Systems Modelling, Potsdam, 14473, Germany \\ ${ }^{2}$ Institute of Geosciences, University of Potsdam, Potsdam, 14476, Germany \\ Correspondence: Maria Wetzel (maria.wetzel@gfz-potsdam.de)
}

Received: 13 June 2020 - Revised: 28 August 2020 - Accepted: 9 September 2020 - Published: 9 October 2020

\begin{abstract}
Cementation of potential reservoir rocks is a geological risk, which may strongly reduce the productivity and injectivity of a reservoir, and hence prevent utilisation of the geologic subsurface, as it was the case for the geothermal well of Allermöhe, Germany. Several field, laboratory and numerical studies examined the observed anhydrite cementation to understand the underlying processes and permeability evolution of the sandstone. In the present study, a digital rock physics approach is used to calculate the permeability variation of a highly resolved three-dimensional model of a Bentheim sandstone. Porosity-permeability relations are determined for reaction- and transport-controlled precipitation regimes, whereby the experimentally observed strong decrease in permeability can be approximated by the transport-limited precipitation assuming mineral growth in regions of high flow velocities. It is characterised by a predominant clogging of pore throats, resulting in a drastic reduction in connectivity of the pore network and can be quantified by a power law with an exponent above ten. Since the location of precipitation within the pore space is crucial for the hydraulic rock properties at the macro scale, the determined porosity-permeability relations should be accounted for in large-scale numerical simulation models to improve their predictive capabilities.
\end{abstract}

\section{Introduction}

Mineral dissolution and precipitation are micro-scale processes, which may significantly alter the internal rock structure and consequently affect the effective hydraulic behaviour of the system at the macro-scale. Predicting changes in rock permeability is of paramount importance for most applications related to geologic subsurface utilisation (Jacquey et al., 2015; Kleinitz et al., 2001; Regenspurg et al., 2015), especially regarding the productivity and injectivity of a reservoir. Permeability is without question the most crucial hydrogeologic parameter, but it is often difficult to determine due to its enormous variation over space and time in natural geological systems (Hommel et al., 2018; Bernabé et al., 2003). Usually, there is a strong positive correlation between porosity and permeability, which can be simply quantified by an exponential equation related to the initial values of porosity and permeability. The relevant exponent varies depending on the represented particular geochemical reaction or hydrothermal reservoir system (Kühn, 2009).

For geothermal exploration, a drill hole was deepened at Allermöhe (Hamburg, Germany) into the Rhaetian sandstones. The originally open pore spaces were found to be filled with anhydrite to a large extent (Baermann et al., 2000a). Therefore, the potential for geothermal exploitation was limited and the drill hole had to be abandoned. Beforehand, extensive studies were performed to reveal insights into the regional distribution of the cementation (Baermann et al., 2000b). Pape et al. (2005) analysed the observed local clogging phenomena due to anhydrite precipitation in the porespace of related drill hole samples and studied the pore size geometry. They distinguished between two facies types with different diagenetic history: (1) a fine-grained and uncemented sand with small pores, mechanically compacted during diagenesis and (2) a coarser sand with larger pores, almost completely cemented by anhydrite after its compaction.

In order to understand the observed anhydrite cementation in the core samples from the borehole at Allermöhe, Wagner et al. (2005) performed fully coupled numerical simulations of reactive flow at the local and regional scales. A reser- 

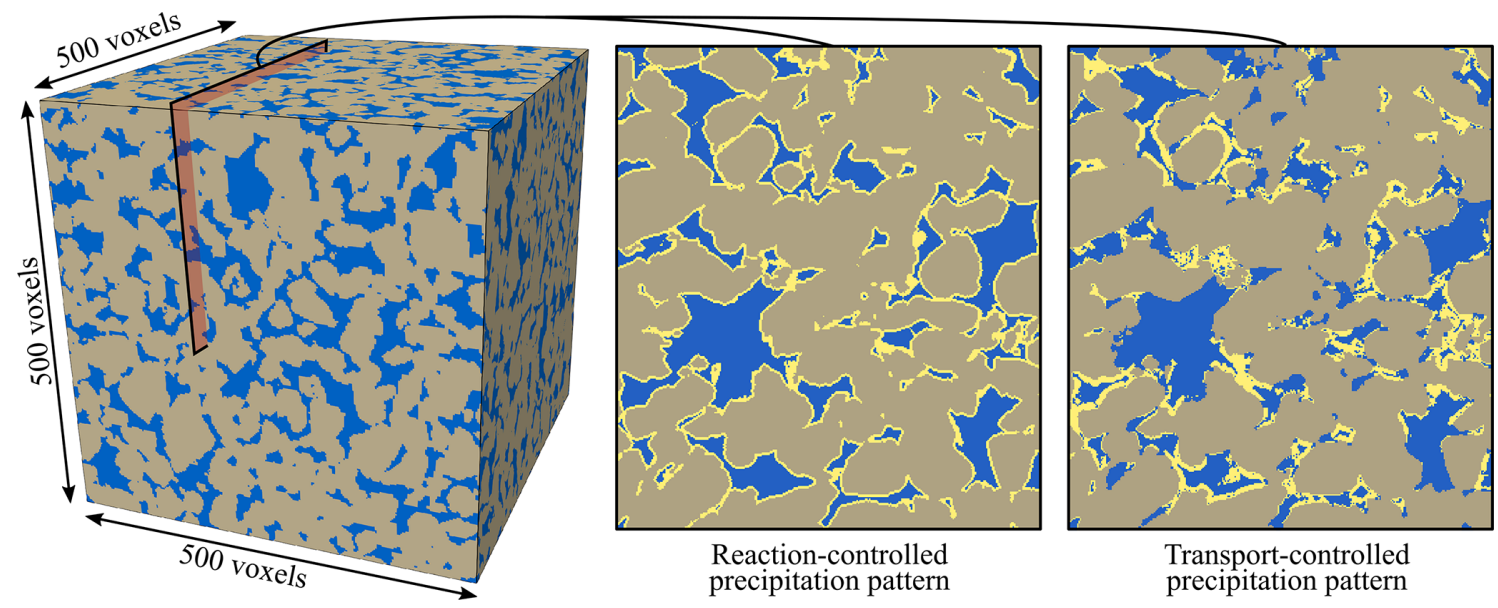

Figure 1. Binarised micro-CT scan of the Bentheim sandstone has an initial porosity of $23 \%$ and comprises pore space (blue) and grains (brown). Exemplary slices through the digital rock show the anhydrite cementation (yellow) for a reaction- and a transport-controlled precipitation at a porosity of $17 \%$.

voir model was used to simulate the chemical stimulation of the sandstone formation via a forced increase in porosity and permeability in the close borehole vicinity. At the reservoir scale, numerical simulations of Kühn and Günther (2007) indicate that strata-bound convective flow in the Rhaetian sandstone reservoir is insufficient to explain the observed high degree of anhydrite cementation. However, it is shown by Wagner et al. (2005) that brine is forced to precipitate around fracture zones, if hot fluids flow up along faults, heating up the aquifer.

A core flooding experiment simulating the conditions in an operated geothermal reservoir was performed to validate the abovementioned numerical models, applied for the Allermöhe site (Bartels et al., 2002). A Bentheim sandstone sample was prepared with anhydrite and subjected to a temperature gradient, while the changes in permeability were measured along the core. Within the cold upstream and hot downstream regions of the core, anhydrite was dissolved and precipitated, respectively.

Within the presented study, we apply a digital rock physics approach to determine if observed anhydrite precipitation in the core flooding experiment of Bartels et al. (2002) and samples of the Allermöhe site (Baermann et al., 2000a; Pape et al., 2005) can be ascribed in particular to a reactionor transport-controlled process. To upscale the chemical reactions from the micro to the macro scale, we determine the required porosity-permeability relationship. The impact of precipitation on the effective hydraulic rock properties is especially of interest for a sustainable utilisation of the geological subsurface and for risk assessment to avoid unsuccessful drilling campaigns like the one at Allermöhe.

\section{Material and methods}

A digital sample of the Bentheim sandstone is used to determine the dominant mechanism of pore space alteration due to anhydrite cementation, since its mechanical and hydraulic properties have been well investigated by several studies (Bakker and Barnhoorn, 2019; Jacquey et al., 2016; Peksa et al., 2015; Wetzel et al., 2018) and it represents a common reference reservoir rock. The microstructure of the Bentheim sandstone derives from a subset of a publicly available micro-CT scan (Herring et al., 2018, 2019) and comprises $500^{3}$ voxels with a resolution of $4.9 \mu \mathrm{m}$ (Fig. 1). The permeability of the binarised 3D image is calculated from the flow field by solving the steady-state Stokes equation by means of the OpenFOAM software package (Weller et al., 1998). The calculation of the pore network is done in Python using the PoreSpy package (Gostick et al., 2019). The investigated digital sample has a porosity of $23.4 \%$, which is comparable to the sandstone of the core flooding experiments used by Bartels et al. (2002) with $24.6 \%$. They simulated conditions in a managed geothermal reservoir and investigated the effect of anhydrite dissolution and precipitation on permeability.

The present digital rock physics approach assumes a flow velocity dependency of mineral precipitation to estimate the porosity-permeability relation instead of performing fullycoupled reactive transport simulations. The voxel-based algorithm converts pore space to minerals, depending on the magnitude of the flow velocity, since it reflects the local pore morphology as well as the connectivity of the entire pore space. Two contrasting scenarios are simulated associated with the general geochemical reaction regimes: (1) a preferential precipitation at high flow velocities ( $>75$ th percentile), which can be associated with a transport-controlled process where the reaction is limited by the availability of re- 

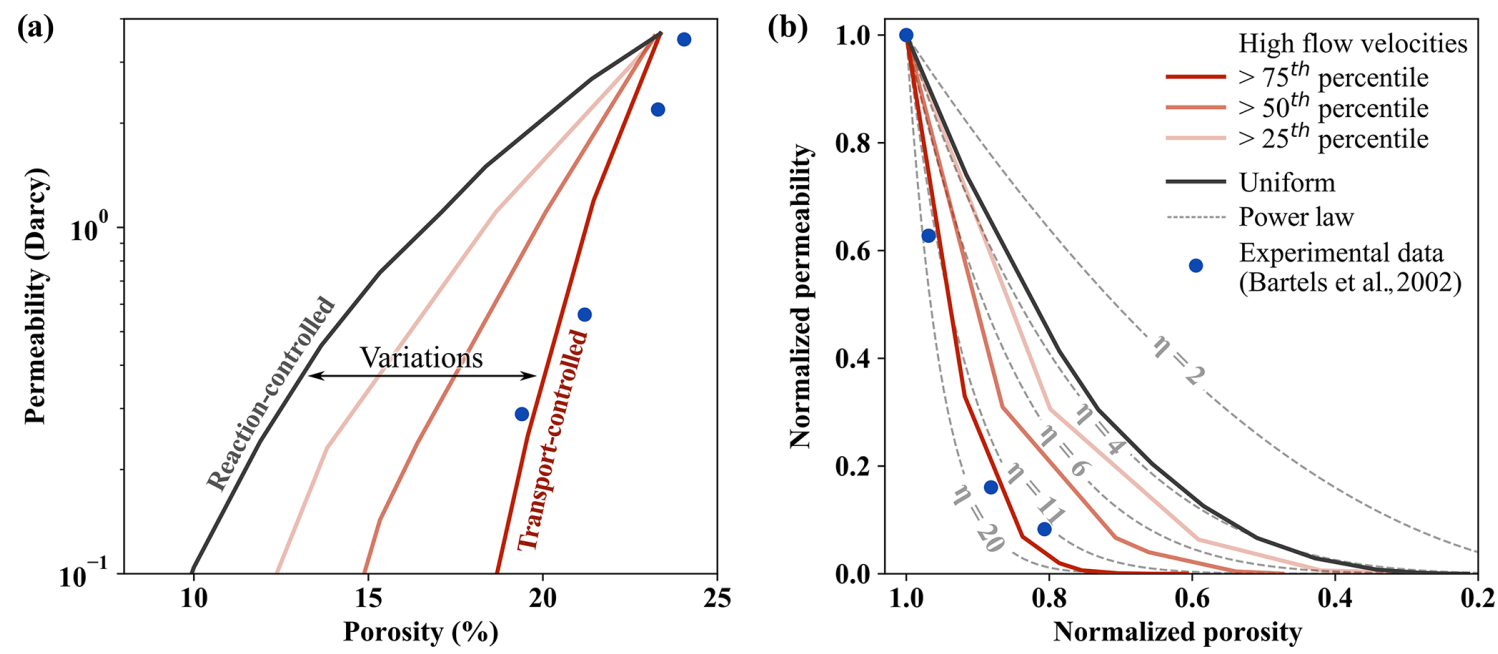

Figure 2. (a) Impact of anhydrite cement on permeability evolution observed during a core flooding experiment of Bartels et al. (2002), compared to the calculated porosity-permeability relations. (b) Normalised results compared to analytical relations by the power law with different exponents $(\eta)$.

Table 1. Porosities and permeabilities along a $0.5 \mathrm{~m}$ Bentheim core observed during a core flooding experiment (Bartels et al., 2002).

\begin{tabular}{lrr}
\hline $\begin{array}{l}\text { Core position } \\
(\mathrm{m})\end{array}$ & $\begin{array}{r}\text { Porosity } \\
(\%)\end{array}$ & $\begin{array}{r}\text { Permeability } \\
\left(10^{-12} \mathrm{~m}^{2}\right)\end{array}$ \\
\hline 0.05 & 24.05 & 3.44 \\
0.25 & 23.3 & 2.16 \\
0.31 & 21.2 & 0.55 \\
0.34 & 19.4 & 0.28 \\
\hline
\end{tabular}

actants transported to the fluid-mineral interface (Noiriel and Daval, 2017), and (2) a uniform precipitation independent of the fluid flow, that represents a surface reaction-controlled process, whereby the chemical reaction rate limits precipitation and pore space alters homogeneously (Fig. 1). A detailed description of the model set-up as well as the iterative precipitation approach is described in Wetzel et al. (2020).

\section{Results}

The geochemical reaction regime strongly impacts the evolution in permeability of the digital rock sample as illustrated by the large variations between transport-controlled and reaction-controlled porosity-permeability relations. In case of precipitation at high flow velocities, a permeability decrease of one order of magnitude occurs for a reduction in porosity to $20 \%$, whereas in the case of a uniform pore alteration this permeability is achieved at a substantially lower porosity of $13.5 \%$ (Fig. 2a). The flow velocity thresholds represent the intensity of the dominant mechanism regarding both contrasting processes and allow for gradation between them. Permeability evolution due to anhydrite cementation in a Bentheim sandstone with comparable initial hydraulic properties as for the chosen digital sample is described by Bartels et al. (2002, Table 1). The observed strong decrease in permeability can be approximated by the simulated porositypermeability relation for a transport-controlled precipitation, assuming mineral growth in regions comprising flow velocities $>75$ th percentile (Fig. 2b). Further, the strong decrease in permeability can be described by a power law with a high exponent $(\eta)$ above 11.3 (Bartels et al., 2002). This is similar to the findings of Baermann et al. (2000a, b), who determined an exponent of around twelve from field samples taken at the Allermöhe well.

Since the experimentally observed permeability changes due to anhydrite cementation can be associated with the simulated transport-controlled precipitation, the digital rock physics approach further allows for quantification of significant alterations in the pore morphology. Noticeable changes in the number and sizes of throats indicate a preferential clogging of pore throats. Compared to the unaffected microstructure, $23 \%$ of the initial pore throats are completely closed at a reduced porosity of $17 \%$. Moreover, the median throat size substantially decreases from 21 to $11 \mu \mathrm{m}$, while particularly the diameter of larger throats is also reduced (Fig. 3a). The mean pore diameter reduces only slightly from 92 to $82 \mu \mathrm{m}$. The pore size distribution becomes more right-skewed and the number of smaller pores considerably increases (Fig. 3b), whereas the absolute number of pores does not change due to precipitation. The reduction in pore diameters at a reduced porosity of $17 \%$ exhibits a broad right-skewed distribution with a median reduction in the pore diameter of $10 \mu \mathrm{m}$. The diagram presented in Fig. $3 \mathrm{c}$, which relates the changes in pore sizes to the initial diameter, demonstrates comparably lower reductions in the diameters of smaller pores than in 
(a)

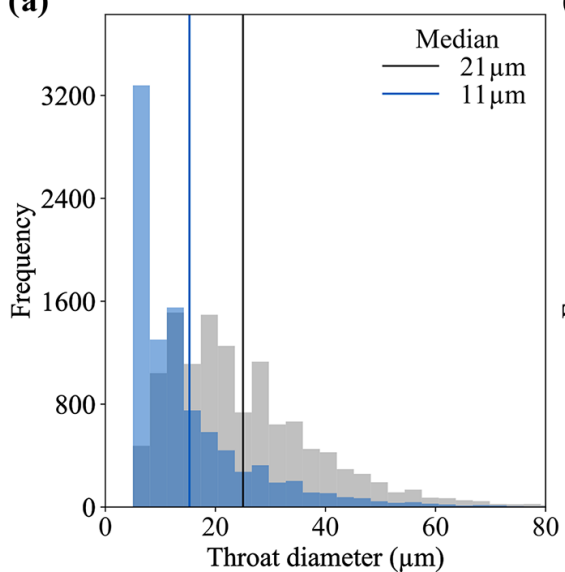

(b)

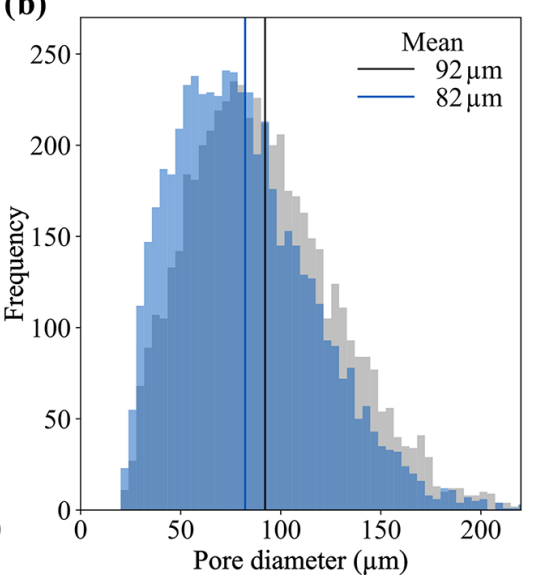

(c)

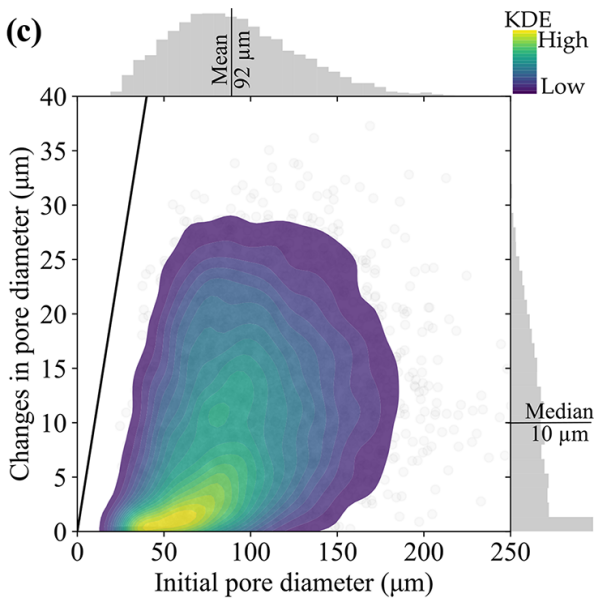

Figure 3. (a) Distribution of the throat and (b) pore diameters for transport-controlled precipitation (blue, $\Phi=17 \%$ ) and the unaffected initial pore morphology (grey, $\Phi=23 \%$ ). (c) Changes in pore diameters depending on the initial pore size for each pore.

those of the larger pores, while none of the pores are completely closed.

The initial flow regime within the pore space of the Bentheim sandstone is highly variable. There are well interconnected regions with preferential flow paths and comparably high flow velocities as illustrated by the streamlines in Fig. 4. The simulated transport-controlled pore alteration strongly impacts the spatial distribution of fluid flow paths and velocities. At a reduced porosity of $21 \%$, flow velocities noticeably decrease. Successive precipitation leads to the progressive closure of flow paths due to the described preferential precipitation in the pore throats. At a porosity of $17 \%$, the majority of initial flow paths are cut-off, and the pore space is considerably less connected (Fig. 4). These results are in accordance with the different facies types found by Pape et al. (2005), but also support the conclusion of Bartels et al. (2000) on the permeability of the Rhaetian sandstone at Allermöhe being particularly reduced due to the narrowing of pore throats as a result of diagenetic anhydrite precipitation.

\section{Discussion and conclusions}

Mining for geothermal heat usually requires at least one or more production and injection wells. These installations are the major capital investments and demand economic feasibility, which mainly depends on the permeability and porosity of the reservoir. A major geological risk is the clogging of the pore space of the reservoir rocks by precipitation of minerals such as anhydrite (Wagner et al., 2005), as it was the case for the deepened Allermöhe, where the Rhaetian sandstone was largely cemented with anhydrite. Consequently, determination of the origin of the anhydrite cement pore fillings represents a basis for exploration to lower the risk for failure for future projects. This is mainly investigated by fully coupled numerical simulations of flow, heat transfer, species transport and chemical reactions at the reservoir scale (Kühn and Günther, 2007; Wagner et al., 2005).

Precipitation reduces porosity in general, but its effect on transport properties strongly depends on its location. Various studies discuss if precipitation preferably occurs in larger pores or in contrast in smaller ones (Stack, 2015; Steinwinder and Beckingham, 2019). For the Allermöhe sandstone, it is presumed that larger pores were favoured for anhydrite precipitation during its diagenesis (Pape et al., 2005). This was also studied by means of a one-dimensional numerical test case carried out by Mürmann et al. (2013), who explained the heterogeneous anhydrite cementation patterns by a variation of the fluid supersaturation and fluid velocity within the pores.

In this study, we present similar results by applying a digital rock physics approach (Wetzel et al., 2020) with the advantage of a significantly higher resolution and representation of the specific porous network of the Bentheim sandstone. Thus, it is possible to adequately predict hydraulic rock properties by characterising the micro structure, morphology and connectivity of pores. In view of a virtual laboratory, digital rock models allows to consider varying distributions of secondary minerals for the same rock sample and can be used to establish trends of evolving geophysical properties, e.g., as consequence of diagenetic processes (Hosa and Wood, 2020; Singh et al., 2020). The results of this study indicate that particularly larger pores are reduced in size by mineral precipitation, as demonstrated by Mürmann et al. (2013). Even though all pore sizes are affected by precipitation, we observe that the amount of smaller pores considerably increases. Hence, the reduction in pore size is limited to a certain size, since pores are successively detached from the high velocity flow field and hence an assured reactant replenishment. Much more important and cru- 

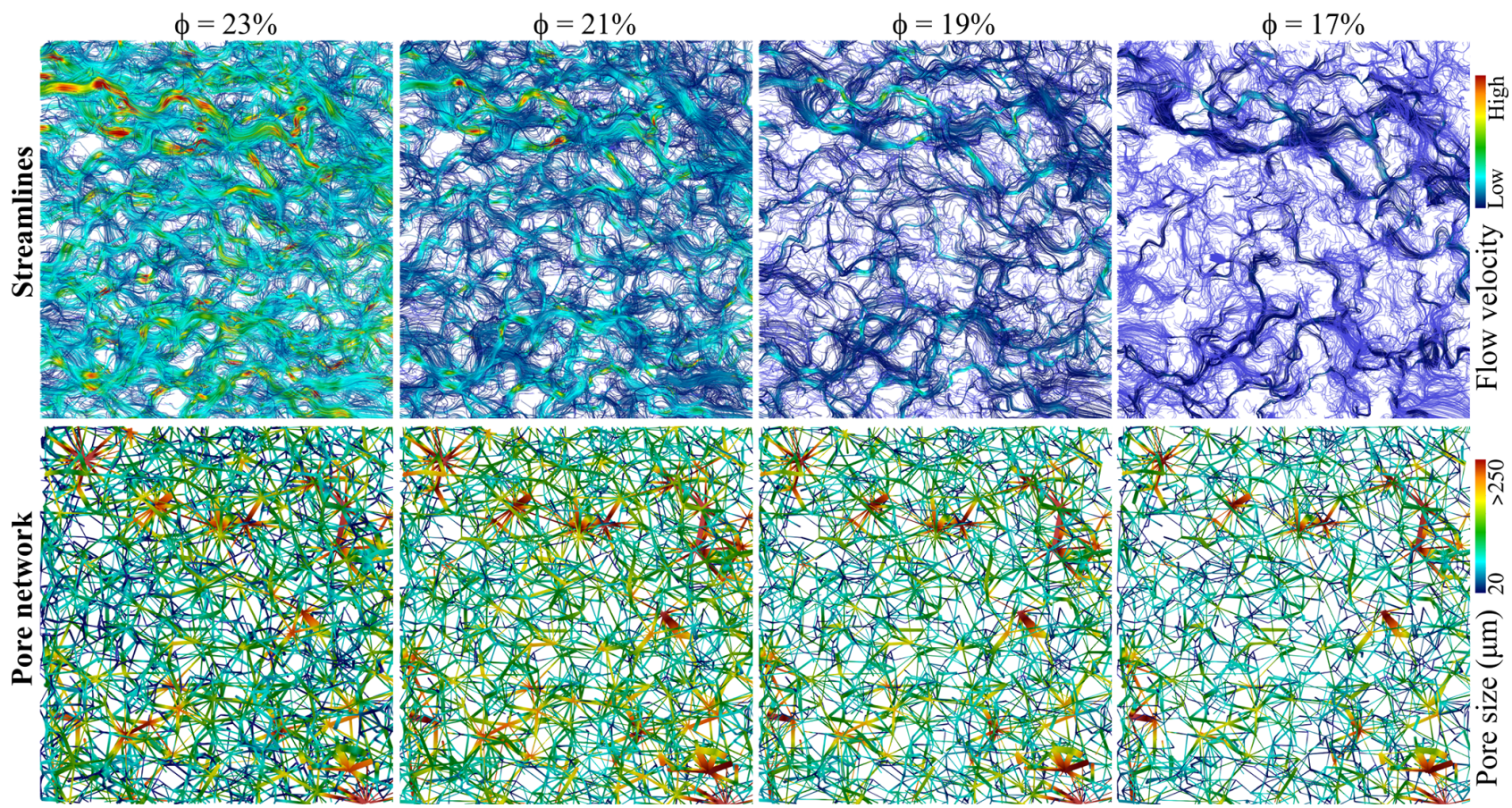

Figure 4. Evolution of the streamlines for flow in $x$ direction (red: high velocities, blue: low velocities) and the pore network (red: high pore diameter, blue: low pore diameter) considering a transport-controlled reaction regime with preferential precipitation in regions of high flow velocities ( $>75$ th percentile).

cial for the permeability development of the Bentheim sandstone are the pore throats. Their clogging is responsible for the steep porosity-permeability relation with an exponent of well above ten.

Of course, mineral precipitation is complex and not exclusively depending on flow velocity. The chemical reaction regime is controlled by various other factors like fluid chemistry, temperature, pressure, mineralogy, pore morphology and transport properties, whereby the impact of each aspect depends on the particular process. Moreover, the presented method bases on a micro-scale representation of the reservoir rock and therefore does not take larger scale heterogeneities into account (e.g. fissures, fractures or facies changes). Nevertheless, it proves to be a simple way to estimate porositypermeability relations conditional to the geochemical reaction regime without the need to apply complex and computationally expensive reactive transport simulations.

We conclude that the applied digital rock physics approach (Wetzel et al., 2020) is a viable model to describe the transport-controlled precipitation of anhydrite in Bentheim sandstones at the micro-scale and quantify changes of the effective porosity and permeability of the rock. Our results coincide with laboratory studies (Bartels et al., 2002), conducted to simulate field observations to reveal insights about the regional distribution of the cementation of the Rhaetian sandstone by anhydrite. The impact of the chemical precipitation regime on the effective hydraulic rock properties can be quantified by a porosity-permeability relation using a dig- ital rock physics approach. These findings can be now applied for the assessment of equivalent reservoirs to succeed with future projects aiming at utilisation of the geological subsurface in the North German Basin.

Data availability. he underling microstructure of the sandstone is publicly available at the Digital Rocks Portal: https://doi.org/10.17612/P7MH3M (Herring et al., 2018).

Author contributions. The three authors have equally contributed to this paper. MW and MK conceived and designed the simulations; MW performed the research; MW, TK and MK analysed the data; MW, MK and TK wrote the paper. All authors read and agreed to the published version of the manuscript.

Competing interests. The authors declare that they have no conflict of interest.

Special issue statement. This article is part of the special issue "European Geosciences Union General Assembly 2020, EGU Division Energy, Resources \& Environment (ERE)". It is a result of the EGU General Assembly 2020, 4-8 May 2020. 
Acknowledgements. We are grateful for the editorial handling and the constructive comments provided by the two anonymous reviewers.

Financial support. This research has been supported by the German Federal Ministry for Education and Research (BMBF) (Geo:N project GEOSMART (grant no. 03G0867E)).

The article processing charges for this open-access publication were covered by a Research Centre of the Helmholtz Association.

Review statement. This paper was edited by Johannes Miocic and reviewed by two anonymous referees.

\section{References}

Baermann, A., Kröger, J., Taugs, R., Wüstenhagen, K., and Zarth, M.: Anhydrite cement in Rhaetian sandstones in southeastern Hamburg: morphologie and structure, Z. angew. Geol., 46, 138144, 2000a (in German).

Baermann, A., Kröger, J., and Zarth, M.: Anhydrite Cement in Rhaetian Sandstones in Hamburg: X-ray and NMR Tomographic Studies and Leaching Tests, Z. angew. Geol., 46, 144-152, 2000b (in German).

Bakker, R. R. and Barnhoorn, A.: Multiscale evaluation of potential damage in jetted lateral boreholes, Int. J. Rock Mech. Min. Sci., 121, 104007, https://doi.org/10.1016/j.ijrmms.2019.03.027, 2019.

Bartels, J., Dietrich, H.-G., Goebbels, J., and Klobes, P.: Analysis of the natural flow path and methods of their stimulation in a cemented aquifer by combination of X-ray computerized tomography with mercury porosimetry, Z. angew. Geol., 46, 153-156, 2000 (in German).

Bartels, J., Kühn, M., Schneider, W., Clauser, C., Pape, H., Meyn, V., and Lajcsak, I.: Core flooding laboratory experiment validates numerical simulation of induced permeability change in reservoir sandstone, Geophys. Res. Lett., 29, 34-1, https://doi.org/10.1029/2002gl014901, 2002.

Bernabé, Y., Mok, U., and Evans, B.: Permeability-porosity relationships in rocks subjected to various evolution processes, Thermo-Hydro-Mechanical Coupling Fract. Rock, 160, 937960, https://doi.org/10.1007/978-3-0348-8083-1_9, 2003.

Gostick, J., Khan, Z., Tranter, T., Kok, M., Agnaou, M., Sadeghi, M., and Jervis, R.: PoreSpy: A python toolkit for quantitative analysis of porous media images, Journal of Open Source Software, 4, 1296, https://doi.org/10.21105/joss.01296, 2019.

Herring, A., Sheppard, A., Turner, M., and Beeching, L.: Multiphase Flows in Sandstones, Digital Rocks Portal, https://doi.org/10.17612/P7MH3M, 2018.

Herring, A., Robins, V., and Sheppard, A. P.: Topological persistence for relating microstructure and capillary fluid trapping in sandstones, Water Resour. Res., 55, 555-573, https://doi.org/10.1029/2018WR022780, 2019.

Hommel, J., Coltman, E., and Class, H.: Porosity-permeability relations for evolving pore space: a review with a focus on (bio-)geochemically altered porous media, Transp. Porous Media, 124, 589-629, https://doi.org/10.1007/s11242-018-1086-2, 2018.

Hosa, A. and Wood, R.: Order of diagenetic events controls evolution of porosity and permeability in carbonates, Sedimentology, 67, 3042-3054, https://doi.org/10.1111/sed.12733, 2020.

Jacquey, A. B., Cacace, M., Blöcher, G., Watanabe, N., and Scheck-Wenderoth, M.: Hydro-mechanical evolution of transport properties in porous media: Constraints for numerical simulations, Transp. Porous Media, 110, 409-428, https://doi.org/10.1007/s11242-015-0564-z, 2015.

Jacquey, A. B., Cacace, M., Blöcher, G., Watanabe, N., Huenges, E., and Scheck-Wenderoth, M.: Thermo-poroelastic numerical modelling for enhanced geothermal system performance: Case study of the Groß Schönebeck reservoir, Tectonophysics, 684, 119-130, https://doi.org/10.1016/j.tecto.2015.12.020, 2016.

Kleinitz, W., Koehler, M., and Dietzsch, G.: The Precipitation of Salt in Gas Producing Wells, SPE - Eur. Form. Damage Control Conf. Proc., 295-301, https://doi.org/10.2523/68953-ms, 2001.

Kühn, M.: Modelling feedback of chemical reactions on flow fields in hydrothermal systems, Surv. Geophys., 30, 233, https://doi.org/10.1007/s10712-009-9055-5, 2009.

Kühn, M. and Günther, A.: Stratabound Rayleigh convection observed in a 4D hydrothermal reactive transport model based on the regional geological evolution of Allermöhe (Germany), Geofluids, 7, 301-312, https://doi.org/10.1111/j.14688123.2007.00182.x, 2007.

Mürmann, M., Kühn, M., Pape, H., and Clauser, C.: Numerical simulation of pore size dependent anhydrite precipitation in geothermal reservoirs, Enrgy. Proced., 40, 107-116, https://doi.org/10.1016/j.egypro.2013.08.014, 2013.

Noiriel, C. and Daval, D.: Pore-Scale Geochemical Reactivity Associated with $\mathrm{CO}_{2}$ Storage: New Frontiers at the Fluid-Solid Interface, Acc. Chem. Res., 50, 759-768, https://doi.org/10.1021/acs.accounts.7b00019, 2017.

Pape, H., Clauser, C., Iffland, J., Krug, R., and Wagner, R.: Anhydrite cementation and compaction in geothermal reservoirs: Interaction of pore-space structure with flow, transport, P-T conditions, and chemical reactions, Int. J. Rock Mech. Min. Sci., 42, 1056-1069, https://doi.org/10.1016/j.ijrmms.2005.05.007, 2005.

Peksa, A. E., Wolf, K. H., and Zitha, P. L.: Bentheimer sandstone revisited for experimental purposes, Mar. Pet. Geol., 67, 701719, https://doi.org/10.1016/j.marpetgeo.2015.06.001, 2015.

Regenspurg, S., Feldbusch, E., Byrne, J., Deon, F., Driba, D. L., Henninges, J., Kappler, A., Naumann, R., Reinsch, T., and Schubert, C.: Mineral precipitation during production of geothermal fluid from a Permian Rotliegend reservoir, Geothermics, 54, 122-135, https://doi.org/10.1016/j.geothermics.2015.01.003, 2015.

Singh, J., Cilli, P., Hosa, A., and Main, I.: Digital rock physics in four dimensions: Simulating cementation and its effect on seismic velocity, Geophys. J. Int., 222, 1606-1619, https://doi.org/10.1093/gji/ggaa271, 2020.

Stack, A. G.: Precipitation in pores: A geochemical frontier, Rev. Mineral. Geochemistry, 80, 165-190, https://doi.org/10.2138/rmg.2015.80.05, 2015.

Steinwinder, J. and Beckingham, L. E.: Role of pore and pore-throat distributions in controlling permeability in heterogeneous min- 
eral dissolution and precipitation scenarios, Water Resour. Res., 55, 5502-5517, https://doi.org/10.1029/2019WR024793, 2019.

Wagner, R., Kühn, M., Meyn, V., Pape, H., Vath, U., and Clauser, C.: Numerical simulation of pore space clogging in geothermal reservoirs by precipitation of anhydrite, Int. J. Rock Mech. Min. Sci., 42, 1070-1081, https://doi.org/10.1016/j.ijrmms.2005.05.008, 2005.

Weller, H. G., Tabor, G., Jasak, H., and Fureby, C.: A tensorial approach to computational continuum mechanics using objectoriented techniques, Comput. Phys., 12, 620-631, 1998.
Wetzel, M., Kempka, T., and Kühn, M.: Quantifying rock weakening due to decreasing calcite mineral content by numerical simulations, Materials, 11, 1-19, https://doi.org/10.3390/ma11040542, 2018.

Wetzel, M., Kempka, T., and Kühn, M.: Hydraulic and mechanical impact of precipitation on a reservoir sandstone quantified by digital rock physics, Materials, 13, 3100, https://doi.org/10.3390/ma13143100, 2020. 